\title{
Implementation of clinical audit to improve adherence to guideline-recommended therapy in acute coronary syndrome
}

\author{
Nimmy Elizabeth George, Aashiq Ahamed Shukkoor, Noel Joseph, Ramasamy Palanimuthu*, \\ Tamilarasu Kaliappan and Rajendiran Gopalan
}

\begin{abstract}
Background: Despite global consensus on the management of acute coronary syndrome (ACS), implementation of strategies to improve adherence of guideline-directed medical therapy (GDMT) remains sub-optimal, especially in developing countries. Thus, we aimed to assess the effect of clinical pharmacist-led clinical audit to improve the compliance of discharge prescriptions in patients admitted with ACS. It is a prospective clinical audit of ACS patients which was carried out for 12 months. The discharge prescriptions were audited by clinical pharmacists for the appropriateness in the usage of statins, dual antiplatelet therapy (DAPT), beta-blockers, and angiotensin-converting enzyme inhibitors (ACE-I)/angiotensin receptor blocker (ARB). A feedback report was presented every month to the cardiologists involved in the patient care, and the trend in the adherence to GDMT was analyzed over 12 months.
\end{abstract}

Results: The discharge prescriptions of 1072 ACS patients were audited for the justifiable and non-justifiable omissions of mandated drugs. The first-month audit revealed unreasonable omissions of DAPT, statin, ACE-I/ARB, and beta-blockers in $1 \%, 0 \%, 14 \%$, and $11 \%$ respectively, which reduced to nil by the end of the 11 th month of the auditfeedback program. This improvement remained unchanged until the end of the 12th month.

Conclusions: The study revealed that periodic clinical audit significantly improves adherence to GDMT in patients admitted with ACS.

Keywords: Acute coronary syndrome, Clinical audit, Evidence-based pharmacy practice, Prescriptions

\section{Background}

ACS is a spectrum of clinical conditions that occur due to myocardial ischemia or infarction that are commonly due to an abrupt reduction in coronary blood flow. It comprises two clinical presentations, namely ST elevation ACS and non-ST elevation ACS [1]. The management of ACS has rapidly evolved worldwide over the past two decades with a better focus on protocol-based pharmacotherapy [2].

*Correspondence: nimgeorge2@gmail.com

Department of Cardiology, PSG Institute of Medical Sciences

and Research, Coimbatore, India
Modern medical treatments like percutaneous coronary intervention (PCI) are proven to have high recovery rates in patients with ACS [3]. Despite these, the survivors are still at high risk for recurrent cardiovascular events. It is estimated that the short-term mortality rate at 30 days after an acute ACS event is between 2 and 3\%, whereas the rehospitalization rate within 30 days is as high as 12 to $25 \%[4,5]$. A significant risk persists, and the key is to reduce the morbidity and mortality risk in ACS with a secondary prevention plan [6]. Patients should inevitably receive appropriate medical management of coronary risk factors irrespective of the state of revascularization. Studies show that pharmacological strategies 
have improved the long-term outcome of patients presenting with ACS $[7,8]$.

The American College of Cardiology/American Heart Association as well as the guidelines by the European Society of Cardiology advocates the collective use of antiplatelets, angiotensin-converting enzyme inhibitors/ angiotensin receptor blockers, beta-blockers, and lipidlowering agents (primarily statins) for long-term treatment of patients after ACS [1,9]. Many registries across the globe project that approximately one-half of patients do not receive recommended treatments after an ACS event [10]. Despite global consensus on the management of ACS, gaps in the implementation of adherence to guideline-directed therapy exist in developing countries [2]. The result from the Indian data on ACS points out that patients are less likely to receive evidence-based treatment. It also emphasizes the sub-optimal medical discharge management of ACS patients in India [11].

The purpose of the current study was to conduct a monthly clinical audit of discharge prescriptions in patients admitted with ACS. The discharge prescriptions were examined for the inclusion of recommended drugs at the recommended dosage, and the unreasonable omission of mandated drugs was highlighted to the cardiologists by clinical pharmacists. The clinical audit-feedback was carried over 1 year, and the impact of monthly clinical audits in improving the prescriptions of evidence-based pharmacotherapy in patients with ACS was analyzed.

\section{Methods}

\section{Study design}

A prospective, unicentric, observational clinical audit of discharge prescriptions of ACS patients was conducted at PSG Hospitals, Coimbatore, Tamil Nadu, after the clearance from the institutional human ethics committee.

\section{Monthly clinical audit}

Adherence to GDMT is an area of prime importance in clinical medicine. Ideally, the discharge prescriptions of patients admitted with ACS should include dual antiplatelet therapy, statin, beta-blocker, and ACE-I/ARB unless contraindicated for a patient in addition to the drugs for other comorbidities. The aforementioned drugs, if missed due to valid reasons, are mentioned in the discharge summary of the patients, to avoid confusion during patient follow-up. The inclusion of the recommended drugs in ACS was audited retrospectively based on the patients' discharge summary. This clinical audit of mandated drugs was conducted as a part of a quality improvement program in the management of ACS patients.

\section{Study population}

The study population included all patients admitted with ACS, under the Department of Cardiology, PSG Hospitals, between June 2019 and June 2020.

\section{Exclusion criteria}

- ACS patients discharged from hospital against medical advice

- Death

\section{Method}

The clinical audit and feedback were conducted by cardiology clinical pharmacists. The report presentation included characteristics of patients, such as gender, age, comorbidities, type of ACS, and details about the inclusion of guideline-directed drugs in the management of ACS.

The omissions of mandated drugs were discussed upon, based on the clinical summary of the patients, and the unreasonable omissions of drugs were highlighted. This audit presentation was carried out at the end of every month to the cardiologists involved in the management of ACS patients over 12 months.

\section{Statistical analysis}

The number of patients with unreasonable omission of DAPT, ACEI/ARB, statins, and beta-blockers were calculated in percentage. Curve estimation analysis was performed to determine the pattern of unreasonable omissions over 1 year. $p$ value was considered to be significant if it was less than 0.05 .

Data were analyzed using IBM SPSS statistics 24 and MS Excel (Microsoft Corp, Redmond, WA).

\section{Results}

A total of 1072 patients were admitted with ACS in the Department of Cardiology between June 2019 and June 2020. The audit of discharge prescriptions was conducted in 1045 ACS patients who were eligible for the study. The study comprised $75.02 \%$ male patients and 24.98\% female patients.

Among the ACS patients included in the study, 522 (49.9\%) constituted STEMI, followed by 327 patients with NSTEMI (31.29\%) and 196 patients with unstable angina $(18.75 \%)$. The mean age (S.D) of the study population was $59.2 \pm 12.4$. The most common comorbidities among the study population were hypertension 
Table 1 Baseline characteristics of patients admitted with acute coronary syndrome

\begin{tabular}{ll}
\hline Characteristics & ACS patients (\%) \\
\hline Age (years) & $59.2 \pm 12.4$ \\
Gender & \\
Male & $784(75.02)$ \\
$\quad$ Female & $261(44.97)$ \\
Comorbidities & \\
Hypertension & 64.6 \\
Diabetes & 59.7 \\
Obese & 1.2 \\
Dyslipidemia & 24.3 \\
Family history of CAD & 9.7 \\
Smoking & 15.8 \\
ACS & \\
STEMI & 522 \\
NSTEMl & 327 \\
Unstable angina & 196 \\
\hline
\end{tabular}

(64.6\%) followed by diabetes mellitus (59.7\%) and dyslipidemia (24.3\%) (Table 1).

\section{Dual antiplatelets}

The first month of audit revealed that DAPT was not included in the discharge prescriptions of $3.4 \%$ of the ACS patients. It was discussed and pointed out that $1 \%$ of patients had unreasonable omission of DAPT. The criteria to omit the drugs were agreed upon by the cardiologists, and the audit was conducted at the end of every month. The clinical audit conducted in the second month revealed a similar picture of irrational omissions of DAPT (1\%). In the subsequent months, the unreasonable omissions of DAPT dropped to nil which remained unchanged throughout the study period (Table 2, Fig. 1). This was statistically significant in curve estimation analysis (Fig. 2a). Reasons for medication omission are described in Table 3.

\section{Statins}

The clinical audit for discharge prescriptions for ACS patients conducted in the first month revealed that all the prescriptions included statins. The audit presentation in the following months revealed $1.4 \%$ of omission in the eighth month which was justified as it was withdrawn temporarily up to short follow-up due to statin-associated muscle symptoms. The findings from successive audits showed nil omissions of statins (Table 2, Fig. 1).

\section{ACE-I/ARB}

ACE-I/ARB was excluded in $15.6 \%$ of discharge prescriptions in the first month of observation, of which $14 \%$ of omissions were unjustified. A remarkable reduction in the omission of ACE-I/ARB (4\%) was observed in the second month. A marginal rise in unreasonable omission in ACE-I/ARB was observed when compared to second month $(8 \%$ in the third month and $6 \%$ in both fourth and fifth months).

The decreasing trend of unwarranted omissions of ACE-I/ARB remained the same in the sixth and seventh months as the preceding months. A decline in the

Table 2 Reasonable and unreasonable omissions of drugs used during the study period

\begin{tabular}{|c|c|c|c|c|c|c|c|c|c|}
\hline \multirow[t]{3}{*}{ Months } & \multicolumn{8}{|c|}{ Not prescribed } & \multirow[t]{3}{*}{ Total no. } \\
\hline & \multicolumn{4}{|c|}{$\begin{array}{l}\text { Reasonable omissions } \\
n(\%)\end{array}$} & \multicolumn{4}{|c|}{$\begin{array}{l}\text { Unreasonable omissions } \\
n(\%)\end{array}$} & \\
\hline & $D A P T$ & STATIN & $A C E I / A R B$ & $B B$ & $D A P T$ & STATIN & $A C E-I / A R B$ & $B B$ & \\
\hline 1 & $2(2.4)$ & 0 & $1(1.6)$ & $7(8.1)$ & $1(1.2)$ & 0 & $14(17)$ & $11(14)$ & 81 \\
\hline 2 & $2(3)$ & 0 & $6(7.6)$ & $5(6.08)$ & $1(1.3)$ & 0 & $4(5.2)$ & $10(13)$ & 76 \\
\hline 3 & $5(5.6)$ & 0 & $9(9.4)$ & $10(10.3)$ & 0 & 0 & $8(9)$ & $7(7.4)$ & 94 \\
\hline 4 & $3(3.2)$ & 0 & $4(4.5)$ & $10(12.3)$ & 0 & 0 & $6(7.3)$ & $7(9)$ & 82 \\
\hline 5 & $9(9.6)$ & 0 & $8(7.9)$ & $8(8.8)$ & 0 & 0 & $6(6.2)$ & $7(7.2)$ & 96 \\
\hline 6 & $4(4.9)$ & 0 & $2(2.4)$ & $4(4.9)$ & 0 & 0 & $6(7.2)$ & $6(7.2)$ & 83 \\
\hline 7 & $6(7.6)$ & 0 & $5(6.4)$ & $4(5.3)$ & 0 & 0 & $6(8)$ & $6(8)$ & 76 \\
\hline 8 & $9(12.5)$ & $1(1.4)$ & 5 (6.6) & $4(5.1)$ & 0 & 0 & $5(7)$ & $4(5.4)$ & 74 \\
\hline 9 & 10 (11.7) & 0 & $6(7.5)$ & $6(4.2)$ & 0 & 0 & $5(6)$ & $2(2.3)$ & 84 \\
\hline 10 & $8(7.9)$ & 0 & $6(5.9)$ & $8(7.7)$ & 0 & 0 & 0 & $2(2)$ & 99 \\
\hline 11 & $11(11.7)$ & 0 & $5(4.9)$ & $8(7.8)$ & 0 & 0 & 0 & 0 & 98 \\
\hline 12 & 0 & $4(4)$ & $6(6.1)$ & $2(2)$ & 0 & 0 & 0 & 0 & 102 \\
\hline Significance & & & & & $P<0.000$ & $P<0.000$ & $P<0.000$ & $P<0.000$ & \\
\hline
\end{tabular}






Fig. 1 Unreasonable omission of evidence-based medications over 12 months. ACEl angiotensin-converting enzyme inhibitor, $A R B$ angiotensin receptor blocker, $B$ beta-blockers

unjustified omissions of ACE-I/ARB was observed in both the eighth and ninth months which showed $5 \%$ of omissions of ACE-I/ARB without genuine reason in comparison with $6 \%$ in the preceding months. The tenthmonth audit was a breakthrough in terms of ACE-I/ARB omissions in which prescriptions of ACS patients with unjustified omissions were nil. This trend remained constant in the 11th and 12th months of the audit (Tables 2, 3, Figs. 1, 2c).

\section{Beta-blockers}

The first month of audit exhibited a high number of beta-blocker omissions, which accounted for $19.1 \%$ of which only $8.1 \%$ was reasonable. The irrational omission of beta-blockers was $10 \%$ in the second month of clinical audit. A sustained decreasing trend of unreasonable omission of beta-blockers was observed in the subsequent months (7\% in the third, fourth as well as fifth months). The unjustified omissions of beta-blockers in the discharge prescriptions in the sixth and seventh months of audit revealed a borderline dip (6\% in both the sixth and seventh months of audit compared to $7 \%$ in the preceding months). A gradual decline in the unreasonable omissions of beta-blocker was observed in the discharge prescriptions of ACS patients in the eighth and ninth months of the audit which revealed a drop from $6 \%$ in the preceding months to $4 \%$ and $2 \%$ in the eighth and ninth months, respectively. At the end of the tenth month of audit, unwarranted exclusion of beta-blockers fell to $2 \%$.

It was noted that, with consistent efforts, the eleventhmonth audit had unreasonable omissions of all mandated drugs to zero. This trend of unreasonable omission in the key pharmacotherapy of ACS was rechecked in the 12th

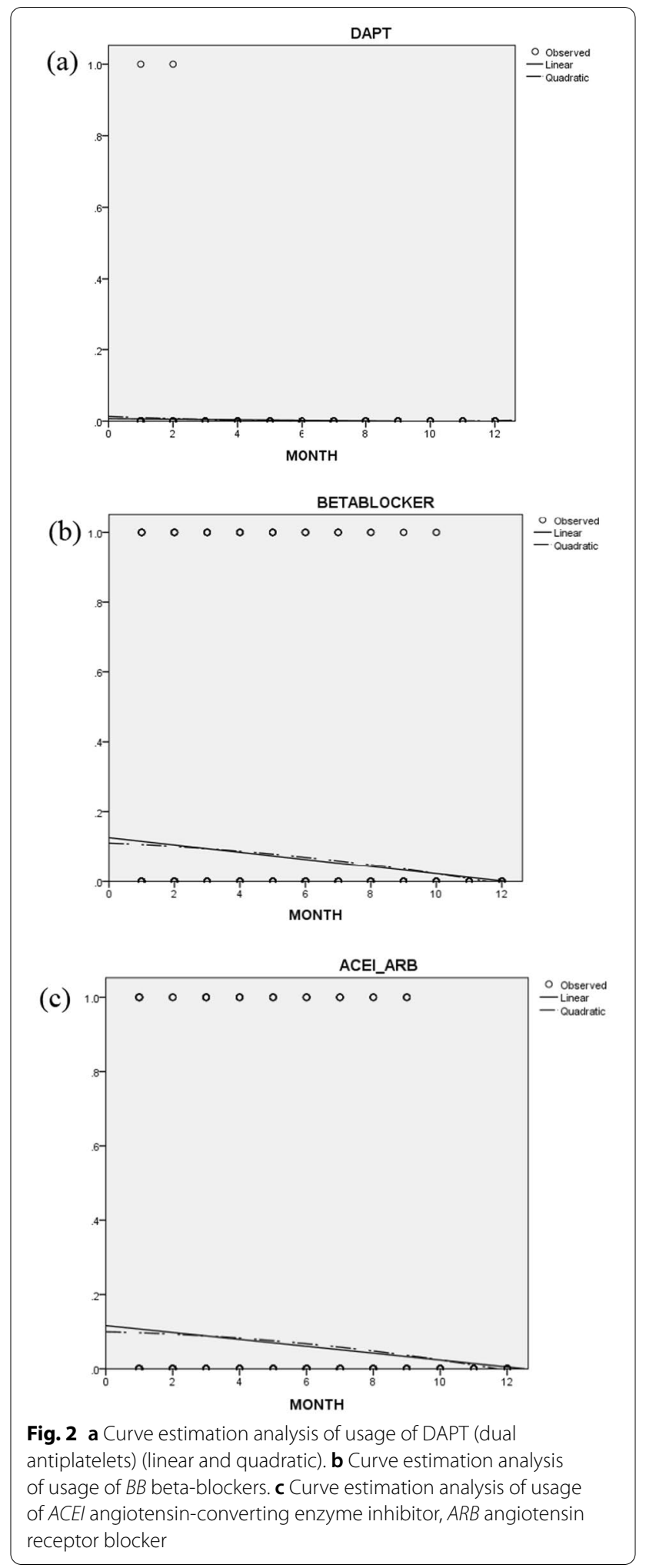


Table 3 Unreasonable medication omission over 12 months

\begin{tabular}{llr}
\hline Drugs & Unjustifiable reason for omission of drugs & N \\
\hline DAPT & Medication omission error by prescriber & 2 \\
ACEI & Borderline blood pressure level & 15 \\
& Borderline potassium level & 7 \\
& Medication omission error by prescriber & 11 \\
& Transcribing error in discharge prescription & 8 \\
& Borderline serum creatinine level & 6 \\
& Contrast-induced nephropathy during hospital & 13 \\
& admission & 19 \\
Beta-blockers & Medication omission error by prescriber & 14 \\
& Non-revascularized RCA & 7 \\
& Fear of worsening lung function in patients with & \\
& COPD & \\
& Apprehensive to initiate beta-blocker and plan to & 22 \\
& introduce at follow-up
\end{tabular}

$D A P T$ dual antiplatelet therapy, $A C E I$ angiotensin-converting enzyme inhibitor, $R C A$ right coronary artery, COPD chronic obstructive pulmonary disease

month of audit which once again revealed nil unreasonable omissions (Tables 2, 3, Figs. 1, 2b).

\section{Discussion}

An optimal secondary prevention plan is indispensable in reducing CVS morbidity and mortality after an ACS event $[12,13]$. Significant risks persist even after a PCI, and continuous efforts are required to reduce these risks, which can be done by optimizing pharmacological treatment at discharge and follow-up [14]. Compliance with the prescription of guideline-recommended therapy constitutes an essential quality benchmark in the management of ACS. Underutilization of GDMT is still prevalent worldwide even in developed countries $[15,16]$.

To the best of our knowledge, this study is the first of its kind in India, highlighting the impact of an ongoing clinical audit of discharge prescriptions in a multidisciplinary forum in improving the adherence to GDMT, resulting in optimal secondary prevention of ACS patients.

In this study, it was observed that in the first month of the audit of discharge prescriptions, only $87.1 \%$ of admitted patients were discharged collectively with all the four mandatory drugs. A study conducted in six Arab countries also revealed that only $49 \%$ of the ACS patients received evidence-based discharge prescriptions [17]. The underutilization of the evidence-based medications is observed not only in developing countries but also in many developed countries of the world. A retrospective cross-sectional study conducted in Australia and Malaysia also reported the underutilization of evidence-based pharmacotherapy in eligible ACS patients [18, 19]. Multiple ACS registries also displayed similar findings [20,21].
The under-prescribing of essential drugs reported in previous studies is often quantified with non-adherence to GDMT. It is important to note that the exclusion of 1 or more guideline-directed pharmacotherapy in ACS does not imply non-optimal therapy. Evidence-based therapy is omitted most often due to justifiable patientspecific contraindications. This study, therefore, aims only to limit the unjustifiable omission of mandated drugs.

Clinical pharmacists are vital in the multidisciplinary management of patients with ACS [22]. A study conducted in Saudi by Amina M. Jabri et al. showed that pharmacist-led review, feedback, and discussion with treating cardiologists improved the prescription of drugs for secondary prevention in ACS from 35 to $80 \%$ [23]. Hassan et al. also reported an increase in the utilization of drugs for secondary prophylaxis with pharmacist's involvement in clinical rounds [24]. Clinical audit has been proven to be an essential quality improvement technique [25]. Thus, we used the expertise of clinical pharmacists to conduct a clinical audit of discharge prescriptions of ACS patients in a monthly presentation in an open forum to the prescribers involved in the care of ACS patients.

Dual antiplatelet is a cornerstone of ACS management [26]. The clinical audit conducted in the first month showed $1 \%$ of the unjustifiable omission of DAPT. Presence of life-threatening bleeding, coagulopathy, thrombocytopenia, aspirin allergy, and immediate surgery such as coronary artery bypass grafting warrants an omission of DAPT. Discussion of the absolute and relative contraindication of antiplatelet drugs helped in the improvement in unjustifiable omission in discharge prescription from $1 \%$ to 0 over 12 months $(p<0.000)$ (Fig. 2a).

Contradictory to the findings of underusage of highintensity statins in ACS in many developed countries, the retrospective audit conducted in the first month of the study period revealed that high-intensity statins were not excluded unreasonably from the discharge prescriptions of ACS patients [27]. Only the efforts to assure the existing adherence pattern had to be carried out in terms of statins, which proved successful.

It is widely known that ACE-I/ARB when initiated after an acute MI reduces mortality, recurrent CVS events, and new-onset heart failure [28]. The findings from a large US-based national registry showed that 1 in 5 eligible patients admitted with ACS failed to receive ACC/ AHA class I-recommended ACE-I/ARB therapy at discharge [29]. Additionally, a study, conducted in Qatar for determining the utilization of evidence-based medication in ACS, also noted sub-optimal usage of ACE-I/ARB in comparison with other drugs [30]. In this study, it is noteworthy that $14 \%$ of eligible patients with diabetes, 
hypertension, chronic kidney disease, heart failure, and LV dysfunction with $\mathrm{EF}<40 \%$ failed to receive ACE-I/ $A R B$ in the first month of observation. Current evidence suggests that physicians are ambivalent in the prescription of ACE-I/ARB probably due to concerns of worsening renal failure or hyperkalemia [31]. Consistent reinforcement of benefits and risks of these drugs with the projection of discharge prescription rates helped in the uptake of these drugs in ACS patients. At the end of 11 months, no eligible patient was discharged without an ACE-I/ARB after an ACS event (Fig. 2c).

Beta-blockers have class I indication in patients with ACS, if not contraindicated [32]. Over 11 months, the prescription rate of beta-blockers in ACS patients increased to $100 \%$. This finding was in line with a study conducted by Hassan et al. which showed increased use of beta-blockers in cardiology units with the help of pharmacist involvement [24]. Our finding was in contrast to a study conducted by Thang Nguyen et al. which demonstrated that interventions targeted at healthcare professionals did not significantly improve the prescribing patterns in ACS except for statins [33] (Fig. 2c).

Compliance with guideline recommendations in ACS discharge management improved significantly with an ongoing audit-feedback presentation by a clinical pharmacist to the prescribing physicians.

\section{Conclusions}

Our study provides an insight into prescription adherence to GDMT in ACS patients. It highlights the ongoing education of caregivers and reinforcement as the best practice for improving adherence to guideline recommendations. This study exhibited the striking reduction in the unjustifiable omission of dual antiplatelets, statins, ACE-I/ARB, and beta-blockers by a clinical pharmacist-led monthly audit presentation to the prescribing cardiologists. Through this study, we recommend the maintenance of GDMT checklist by clinical pharmacist before patient discharge along with clinical audit of discharge prescriptions as the best practice to improve quality of care in patients with ACS.

\footnotetext{
Abbreviations

ACEl: Angiotensin-converting enzyme inhibitor; ARB: Angiotensin receptor blocker; DAPT: Dual antiplatelet; BB: Beta-blocker; $n$ : Number of patients; ARNI: Angiotensin receptor neprilysin inhibitor; ACS: Acute coronary syndrome; STEMI: ST elevated myocardial infarction; NSTEMI: Non-ST elevated myocardial infarction.
}

\section{Acknowledgements}

Not applicable.

\section{Authors' contributions}

All authors contributed to the research equally. AA and NJ collected the data based on the inclusion criteria and analyzed the results. NE drafted the manuscript as per journal requirements. RP, RG, and TK supervised and coordinated the work and revised the final edition of the manuscript. AA contributed to statistical analysis. All authors read and approved the final manuscript.

Funding

The author of this manuscript declares not receiving any fund for this project.

Availability of data and materials

The manuscript data are available on request to the corresponding author.

\section{Declarations}

Ethics approval and consent to participate

Patients were included after written consent was signed by the patients. The institutional human ethics committee of PSG Institute of Medical Sciences and Research gave approval number (20/135).

\section{Consent for publication}

Not applicable.

\section{Competing interests}

The author declares that there are no competing interests.

Received: 8 May 2021 Accepted: 23 December 2021

Published online: 12 January 2022

\section{References}

1. Amsterdam EA, Wenger NK, Brindis RG, Casey DE Jr, Ganiats TG, Holmes DR Jr et al (2014) 2014 AHA/ACC guideline for the management of patients with non-ST-elevation acute coronary syndromes: a report of the American College of Cardiology/American Heart Association Task Force on Practice Guidelines. J Am Coll Cardiol 64(24):e139-e228

2. Guha S, Sethi R, Ray S, Bahl VK, Shanmugasundaram S, Kerkar P et al (2017) Cardiological Society of India: position statement for the management of ST elevation myocardial infarction in India. Indian Heart J 69(Suppl 1):S63-S97

3. Bhagwat MM, Woods JA, Dronavalli M, Hamilton SJ, Thompson SC (2016) Evidence-based interventions in primary care following acute coronary syndrome in Australia and New Zealand: a systematic scoping review. BMC Cardiovasc Disord 16(1):214

4. Roe MT, Messenger JC, Weintraub WS, Cannon CP, Fonarow GC, Dai D et al (2010) Treatments, trends, and outcomes of acute myocardial infarction and percutaneous coronary intervention. J Am Coll Cardiol 56(4):254-263

5. Tobbia P, Brodie BR, Witzenbichler B, Metzger C, Guagliumi G, Yu J et al (2013) Adverse event rates following primary PCI for STEMI at US and non-US hospitals: 3-year analysis from the HORIZONS-AMI trial. Eurolntervention 8(10):1134-1142

6. Jones K, Saxon L, Cunningham W, Adams P, Guideline Development Group (2013) Secondary prevention for patients after a myocardial infarction: summary of updated NICE guidance. BMJ 347:f6544

7. Fox KA (2004) Management of acute coronary syndromes: an update. Heart 90(6):698-706

8. Braunwald E, Antman EM, Beasley JW, Califf RM, Cheitlin MD, Hochman JS et al (2002) American College of Cardiology; American Heart Association. Committee on the Management of Patients with Unstable Angina. ACC/AHA 2002 guideline update for the management of patients with unstable angina and non-ST-segment elevation myocardial infarction-summary article: a report of the American College of Cardiology/ American Heart Association task force on practice guidelines (Committee on the Management of Patients With Unstable Angina). J Am Coll Cardiol 40(7):1366-1374

9. Ibanez B, James S, Agewall S, Antunes MJ, Bucciarelli-Ducci C, Bueno $\mathrm{H}$ et al (2018) ESC Scientific Document Group. 2017 ESC guidelines for the management of acute myocardial infarction in patients presenting with ST-segment elevation: the Task Force for the management of acute myocardial infarction in patients presenting with ST-segment elevation of the European Society of Cardiology (ESC). Eur Heart J 39(2):1 19-177 
10. Simms AD, Weston CF, West RM, Hall AS, Batin PD, Timmis A et al (2015) Mortality and missed opportunities along the pathway of care for STelevation myocardial infarction: a national cohort study. Eur Heart J Acute Cardiovasc Care 4(3):241-253

11. Xavier D, Pais P, Devereaux PJ, Xie C, Prabhakaran D, Reddy KS et al (2008) CREATE registry investigators. Treatment and outcomes of acute coronary syndromes in India (CREATE): a prospective analysis of registry data. Lancet 371(9622):1435-1442

12. Bramlage P, Messer C, Bitterlich N, Pohlmann C, Cuneo A, Stammwitz E et al (2010) The effect of optimal medical therapy on 1-year mortality after acute myocardial infarction. Heart 96(8):604-609

13. Nassr OA, Forsyth P, Johnson CF (2019) Evaluation of discharge prescriptions for secondary prevention in patients with acute coronary syndromes in Iraq. Pharm Pract (Granada) 17(1):1372

14. Kytö V, Prami T, Khanfir H, Hasvold P, Reissell E, Airaksinen J (2019) Usage of $\mathrm{PCl}$ and long-term cardiovascular risk in post-myocardial infarction patients: a nationwide registry cohort study from Finland. BMC Cardiovasc Disord 19(1):123

15. Makam RC, Erskine N, McManus DD, Lessard D, Gore JM, Yarzebski J et al (2016) Decade-long trends (2001 to 2011) in the use of evidence-based medical therapies at the time of hospital discharge for patients surviving acute myocardial infarction. Am J Cardiol 118(12):1792-1797

16. Lee HY, Cooke CE, Robertson TA (2008) Use of secondary prevention drug therapy in patients with acute coronary syndrome after hospital discharge. J Manag Care Pharm 14(3):271-280

17. Al-Zakwani I, Zubaid M, Panduranga P, Rashed W, Sulaiman K, Almahmeed W et al (2011) Medication use pattern and predictors of optimal therapy at discharge in 8176 patients with acute coronary syndrome from 6 Middle Eastern countries: data from the gulf registry of acute coronary events. Angiology 62(6):447-454

18. Vermeer NS, Bajorek BV (2008) Utilization of evidence-based therapy for the secondary prevention of acute coronary syndromes in Australian practice. J Clin Pharm Ther 33(6):591-601

19. Kassab YW, Hassan Y, Aziz NA, Akram H, Ismail O (2013) Use of evidencebased therapy for the secondary prevention of acute coronary syndromes in Malaysian practice. J Eval Clin Pract 19(4):658-663

20. Byeon HJ, Yang YM, Choi EJ (2016) Optimal medical therapy for secondary prevention after an acute coronary syndrome: 18-month follow-up results at a tertiary teaching hospital in South Korea. Ther Clin Risk Manag 12:167-175

21. Quilliam BJ (2008) Suboptimal utilization of secondary drug prevention in acute coronary syndrome: measurement issues and managed care opportunities. J Manag Care Pharm 14(3):312-315

22. El Hajj MS, Jaam MJ, Awaisu A (2018) Effect of pharmacist care on medication adherence and cardiovascular outcomes among patients postacute coronary syndrome: a systematic review. Res Social Adm Pharm 14(6):507-520

23. Jabri AM, Assad HC, Al-Jumaili AA (2020) Pharmacist role to enhance the prescribing of hospital discharge medications for patients after heart attack. Saudi Pharm J 28(4):473-479

24. Hassan Y, Kassab Y, Abd Aziz N, Akram H, Ismail O (2013) The impact of pharmacist-initiated interventions in improving acute coronary syndrome secondary prevention pharmacotherapy prescribing upon discharge. J Clin Pharm Ther 38(2):97-100

25. Esposito P, Dal Canton A (2014) Clinical audit, a valuable tool to improve quality of care: general methodology and applications in nephrology. World J Nephrol 3(4):249-255

26. Marcucci R, Patti G, Calabrò P, Gori AM, Grossi G, Cirillo P et al (2019) Antiplatelet treatment in acute coronary syndrome patients: real-world data from the START-Antiplatelet Italian Registry. PLoS ONE 14(7):e0219676

27. Kim MJ, Jeon DS, Gwon HC, Kim SJ, Chang K, Kim HS et al (2012) Korean MUSTANG Investigators. Current statin usage for patients with acute coronary syndrome undergoing percutaneous coronary intervention: multicenter survey in Korea. Clin Cardiol 35(11):700-706

28. Ong HT, Ong LM, Ho JJ (2013) Angiotensin-converting enzyme inhibitors (ACEls) and angiotensin-receptor blockers (ARBs) in patients at high risk of cardiovascular events: a meta-analysis of 10 randomised placebocontrolled trials. ISRN Cardiol. 2013:478597

29. Bainey KR, Armstrong PW, Fonarow GC, Cannon CP, Hernandez AF, Peterson ED et al (2014) Use of renin-angiotensin system blockers in acute coronary syndromes: findings from Get With the Guidelines-Coronary Artery Disease Program. Circ Cardiovasc Qual Outcomes 7(2):227-235

30. El-Hajj MS, Saad A, Al-Suwaidi J, Al-Marridi WZ, Elkhalifa DH, Mohamed AA et al (2016) Utilization of evidence-based secondary prevention medications at the time of discharge in patients with acute coronary syndrome (ACS) in Qatar. Curr Vasc Pharmacol 14(4):394-403

31. Nhat MG, Hai HN, Ngoc-Hoa C (2020) Renal kinetics in acute heart failure. Open Heart. 7(1):e001173

32. Noble S, Roffi M (2017) Routine beta-blocker administration following acute myocardial infarction: why still an unsolved issue? J Thorac Dis 9(11):4191-4194

33. Nguyen $T$, Nguyen $H Q$, Widyakusuma NN, Nguyen $T H$, Pham TT, Taxis $K$ (2018) Enhancing prescribing of guideline-recommended medications for ischaemic heart diseases: a systematic review and meta-analysis of interventions targeted at healthcare professionals. BMJ Open 8(1):e018271

\section{Publisher's Note}

Springer Nature remains neutral with regard to jurisdictional claims in published maps and institutional affiliations.

\section{Submit your manuscript to a SpringerOpen ${ }^{\circ}$ journal and benefit from:}

- Convenient online submission

- Rigorous peer review

- Open access: articles freely available online

- High visibility within the field

- Retaining the copyright to your article

Submit your next manuscript at $\boldsymbol{\nabla}$ springeropen.com 